\title{
ARTICLE
}

\section{Anion-capped metallohost allows extremely slow guest uptake and on-demand acceleration of guest exchange}

\author{
Yoko Sakata ${ }^{1}$ Chiho Murata ${ }^{1} \&$ Shigehisa Akine ${ }^{1}$
}

The switching of molecular recognition selectivity is important for tuning molecular functions based on host-guest binding. While the switching processes in artificial functional molecules are usually driven by changes of the thermodynamic stabilities, non-equilibrium phenomena also play an important role in biological systems. Thus, here we designed a host-guest system utilizing a non-equilibrium kinetically trapped state for on-demand and time-programmable control of molecular functions. We synthesized a bis(saloph) macrocyclic cobalt(III) metallohost $\mathbf{1}(\mathrm{OTf})_{2}$, which has anion caps at both sides of the cation-binding site. The anion caps effectively retard the guest uptake/release so that we can easily make a non-equilibrium kinetically trapped state. Indeed, we can obtain a long-lived kinetically trapped state $\left\{[\mathbf{1 0 K}]^{3+}+\mathrm{La}^{3+}\right\}$ prior to the formation of the thermodynamically more stable state $\left\{[\mathbf{1} \bullet \mathrm{La}]^{5+}+\mathrm{K}^{+}\right\}$. The guest exchange to the more stable state from this kinetically trapped state is significantly accelerated by exchange of $\mathrm{TfO}^{-}$anion caps by $\mathrm{AcO}^{-}$in an on-demand manner.

\footnotetext{
${ }^{1}$ Graduate School of Natural Science and Technology, Kanazawa University, Kakuma-machi, Kanazawa 920-1192, Japan. Correspondence and requests for materials should be addressed to S.A. (email: akine@se.kanazawa-u.ac.jp).
} 
T he switching of molecular recognition selectivity is important for tuning molecular functions based on host-guest binding ${ }^{1-5}$. Most of these switching processes are driven by a stimuli-responsive guest uptake/release or guest exchange upon the structural change between two different states. To date, a number of responsive molecular recognition systems has been developed by taking advantage of various kinds of stimuli such as redox reactions ${ }^{6-8}$, acid/base reactions ${ }^{9-11}$, light irradiation $^{12-15}$ and metal ion addition ${ }^{16,17}$, which lead to drastic structural changes in the host scaffold. Such stimuli-responsive systems can also be found in nature, as represented by $\mathrm{Na}^{+} / \mathrm{K}^{+}$. ATPase, which pumps $\mathrm{Na}^{+}$out of a cell with the concomitant transport of $\mathrm{K}^{+}$into the cell against their concentration gradients with the aid of $\mathrm{ATP}^{18,19}$. The key for regulating the concentrations is the structural changes in the enzyme between the two main states, E1 and E2, which selectively bind $\mathrm{Na}^{+}$and $\mathrm{K}^{+}$, respectively. In general, the selectivity switching requires reversal of the thermodynamic stabilities, which can be evaluated by the association constants, $K_{\mathrm{a}}$, in the two different states (Fig. 1a).

In addition, non-equilibrium phenomena play an important role in biological systems as well as in supramolecular polymer systems $^{20-30}$. For example, passive transport finely controls ion uptake and release using ion channels and carriers according to their concentration gradients. We could make similar ion uptake/release systems using much simpler artificial host molecules if we can access a suitable non-equilibrium kinetically trapped state (Fig. 1b(i)). Once a kinetically trapped state is generated, removal of the kinetic barrier would initiate the uptake/release of guest ions according to the intrinsic affinity difference of the host molecule (Fig. 1b(ii)). This would enable us to tune the molecular functions in an on-demand and time-programmable manner as seen in biological systems. However, such a guest uptake/release based on a kinetically trapped state has rarely been utilized for controlling molecular functions in artificial systems. As to generating a kinetically trapped state as the first step (Fig. 1b(i)), there have been several host molecules that temporarily bind a kinetically favoured guest prior to the binding with a thermodynamically favoured guest $^{31-43}$. Therefore, we envisioned a kinetically trapped host-guest system having the second step in which removal of the kinetic barrier can initiate the guest uptake or exchange (Fig. 1b(ii)).

We designed a host molecule $\left[\mathrm{LCo}_{2}\left(\mathrm{CH}_{3} \mathrm{NH}_{2}\right)_{4}\right](\mathrm{OTf})_{2}$ $\left(=\mathbf{1}(\mathrm{OTf})_{2}\right)$ containing an 18-crown-6-like cavity suitable for cation recognition ${ }^{44,45}$. The molecule has two octahedral cobalt(III) centres and four axially coordinating methylamine molecules as anchors, which would contribute to holding anionic species at the capping sites (Fig. 1c). The anion caps are expected to block the guest from entering and exiting the cavity, and work as a removable kinetic barrier (Fig. 1d). In this paper, we report an ion recognition system that shows an extremely slow uptake of guest cations due to the blocking effect of the anion caps. This enables us to obtain a kinetically trapped state, from which on-demand acceleration of the guest exchange is triggered by the anion cap exchange.

\section{Results}

Synthesis of anion-capped metallohost. The metallohost $\mathbf{1}(\mathrm{OTf})_{2}$ was synthesized by the complexation of the bis(saloph) macrocyclic host $^{44,45} \quad\left(\mathrm{H}_{2}\right.$ saloph $=N, N^{\prime}$-disalicylidene-o-phenylenediamine $)$ with cobalt(II) acetate under aerobic conditions in the presence of methylamine (Supplementary Fig. 1). Each of the two saloph moieties accommodates a low-spin diamagnetic cobalt(III) ion, to which two methylamine molecules coordinate to form an octahedral geometry. A crystallographic analysis revealed its molecular structure in which the central $\mathrm{O}_{6}$ cavity remains vacant as similarly observed in the nickel(II) analogue ${ }^{44,45}$. The four methylamine molecules coordinate to the octahedral cobalt(III) centres to form the capping sites as expected, but the triflate counteranions were not located at the capping sites (Supplementary Fig. 15).

Guest recognition behaviour. We were initially skeptical about the idea that the dicationic metallohost $\mathbf{1}^{2+}$ would bind cationic guests because electrostatic repulsion between the positive charges was expected. However, $\mathbf{1}^{2+}$ showed an excellent binding affinity towards cationic guests. For example, the addition of 1 equiv of $\mathrm{NaOTf}$ to the metallohost $\mathbf{1}(\mathrm{OTf})_{2}$ in $\mathrm{CD}_{3} \mathrm{OD}$ resulted in complete conversion to the inclusion complex $[\mathbf{1} \bullet \mathrm{Na}]^{3+}$ (Fig. $2 \mathrm{a}$ and Supplementary Fig. 2). It is noteworthy that the ${ }^{1} \mathrm{H}$ NMR signals for the inclusion complex were separately observed from those for the free metallohost $\mathbf{1}^{2+}$. This indicated that the complexation/decomplexation process is slow on the NMR timescale. This slow guest exchange would be due to the anion caps as we had expected. Indeed, the X-ray crystallographic analysis of the $\mathrm{Na}^{+}$complex (Fig. 2b) clearly showed that the counteranions are located at the capping sites. The $\mathrm{Na}^{+}$ion was located in the central $\mathrm{O}_{6}$ site, and the two triflate anions at the capping sites coordinate to the guest $\mathrm{Na}^{+}$ion from both sides of the macrocycle. In addition, the anions are hydrogen-bonded to the methylamine molecules as the anchors. The strong interaction between these triflate counteranions and guest $\mathrm{Na}^{+}$ion is probably one of the important factors for the unexpectedly strong cation-binding affinity to overcome the electrostatic repulsion between the positive charges.

Thermodynamics and kinetics of cation recognition. While the metallohost $\mathbf{1}(\mathrm{OTf})_{2}$ did not interact with the smaller ions $\left(\mathrm{Mg}^{2+}, \mathrm{Li}^{+}\right)$, it strongly recognized metal ions having radii of $>1.26 \AA$ (Supplementary Figs 3-11). In particular, the association constants for metal ions having ionic radii of $\sim 1.3 \AA$ $\left(\mathrm{Ca}^{2+}, \mathrm{La}^{3+}, \mathrm{Na}^{+}\right.$and $\left.\mathrm{K}^{+}\right)$were greater than $10^{6} \mathrm{M}^{-1}$ (Table 1, equations (1) and (2)).

$$
\begin{gathered}
\mathbf{1}^{2+}+\mathrm{M}^{n+} \underset{k_{\text {out }}}{\stackrel{k_{\text {in }}}{\rightleftarrows}}[\mathbf{1} \bullet \mathrm{M}]^{(2+n)+} \\
K_{\mathrm{a}}=\frac{\left[[\mathbf{1} \bullet \mathrm{M}]^{(2+n)+}\right]}{\left[\mathbf{1}^{2+}\right]\left[\mathrm{M}^{n+}\right]}=\frac{k_{\text {in }}}{k_{\text {out }}}
\end{gathered}
$$

The binding strengths seem to be mainly governed by the size-fit principle rather than the electrostatic interactions, although the binding strengths might be influenced by some other factors such as the charge of the guest ions. Even multivalent metal ions, such as $\mathrm{Ca}^{2+}$ or $\mathrm{La}^{3+}$, were strongly bound to the dicationic metallohost $\mathbf{1}(\mathrm{OTf})_{2}$ in spite of the expected electrostatic repulsion. This unexpectedly strong binding can be ascribed to the interaction with the anion caps as observed for the $\mathrm{Na}^{+}$complex (for the X-ray crystal structures of the $\mathrm{K}^{+}$and $\mathrm{Ca}^{2+}$ complexes, see Supplementary Figs 17 and 18).

As expected based on the structures of the host-guest complexes having anion caps, the guest uptake and release were extremely slow. For example, the uptake of better guests, such as $\mathrm{K}^{+}, \mathrm{Na}^{+}$and $\mathrm{Ca}^{2+}$, was slow on the NMR timescale (Table 1). Nevertheless, the guest uptake was completed and reached equilibrium within $5 \mathrm{~min}$ after mixing the guests with $\mathbf{1}(\mathrm{OTf})_{2}$. In stark contrast, the complexation with $\mathrm{La}(\mathrm{OTf})_{3}$ was exceptionally slow (Supplementary Fig. 13). It took $120 \mathrm{~h}$ for complete encapsulation after the addition of 2 equiv of $\mathrm{La}(\mathrm{OTf})_{3}$. The half-life of the guest uptake was roughly estimated to be $\sim 10 \mathrm{~h}$ from the time course analysis of the ${ }^{1} \mathrm{H}$ NMR spectra. Thus, the 
a

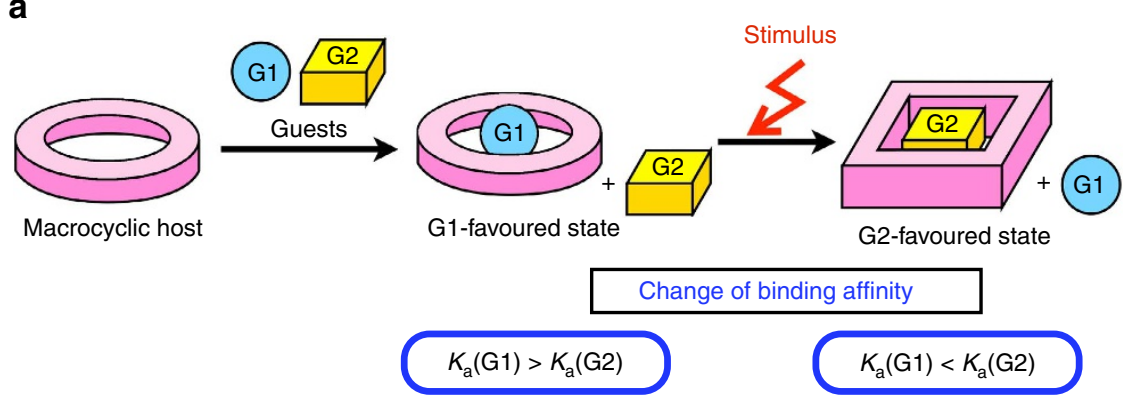

b

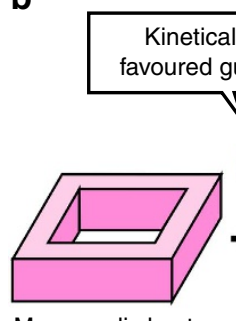

Macrocyclic host (i)

(i)

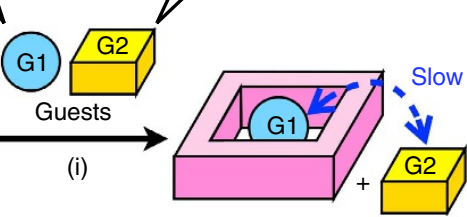

Kinetically trapped state

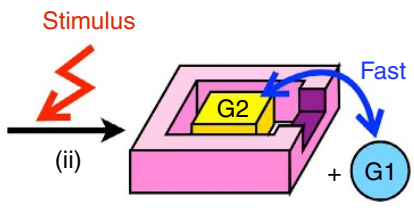

Thermodynamically favoured state

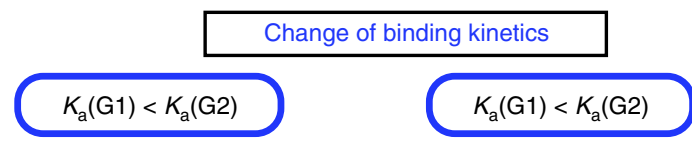

C

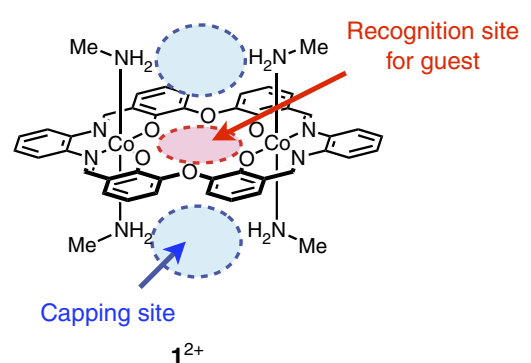

d

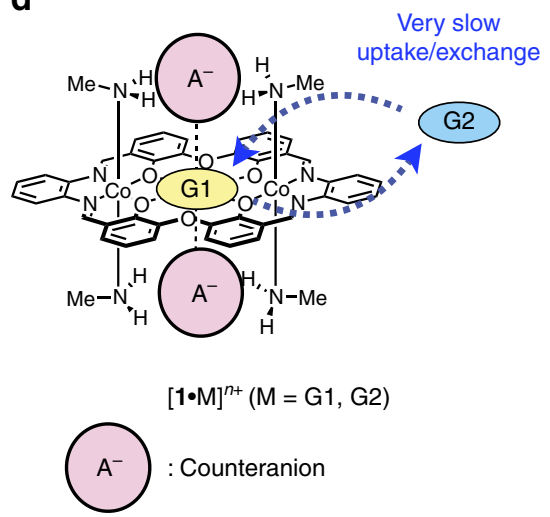

Figure 1 | Design and concept for kinetically controlled on-demand acceleration of guest uptake/exchange. (a) Schematic illustration of thermodynamically controlled stimuli-responsive guest exchange in which the association constants for two different of guests are reversed by an external stimulus. (b) Schematic illustration of kinetically controlled stimuli-responsive guest exchange in which the kinetic barrier for the guest exchange is removed by an external stimulus. (c) Design of macrocyclic host $\mathbf{1}^{2+}$ with two capping sites. (d) Concept of the extremely slow guest uptake/exchange by taking advantage of anion caps.

guest inclusion by $\mathbf{1}(\mathrm{OTf})_{2}$ was much slower than that by simple crown ethers (within milliseconds to seconds) ${ }^{46-48}$. The retarded guest inclusion should mainly be attributed to the effect of the anion caps, although there are differences in the charge and the host structures that could also affect the guest uptake rates.

On-demand acceleration of guest exchange. We expected that this exceptionally slow uptake of $\mathrm{La}^{3+}$ is due to the capping effect of the triflate anions. We thus expected that the guest uptake rates can be tuned by changing the counteranions because the capping effect might depend on the sizes and basicity of the anions. It was inferred that it would be easy to understand the effect of counteranions if we could start with the metallohost having non-coordinating anion such as $\mathrm{BPh}_{4}^{-}$. However, it was difficult to obtain pure sample of $\mathbf{1}\left(\mathrm{BPh}_{4}\right)_{2}$. Thus, 3 equiv of $\mathrm{Bu}_{4} \mathrm{NX}$ $\left(\mathrm{X}=\mathrm{AcO}^{-}, \mathrm{F}^{-}, \mathrm{Cl}^{-}, \mathrm{Br}^{-}, \mathrm{BF}_{4}^{-}, \mathrm{PF}_{6}^{-}, \mathrm{BPh}_{4}^{-}\right)$was added to the mixture of $\mathbf{1}(\mathrm{OTf})_{2}$ and $\mathrm{La}(\mathrm{OTf})_{3}$ and the uptake rates were compared with the blank experiment. As we expected, acetate ion $\left(\mathrm{AcO}^{-}\right)$significantly accelerated the cation uptake, while other anions $\left(\mathrm{F}^{-}, \mathrm{Cl}^{-}, \mathrm{Br}^{-}, \mathrm{BF}_{4}^{-}, \mathrm{PF}_{6}^{-}, \mathrm{BPh}_{4}^{-}\right)$did not. This acceleration was also observed when $\mathrm{La}(\mathrm{OAc})_{3}$ was used as the $\mathrm{La}^{3+}$ source. The uptake of $\mathrm{La}^{3+}$ was completed within $5 \mathrm{~min}$ after the addition of 2 equiv of $\mathrm{La}(\mathrm{OAc})_{3}$ (Supplementary Figs 12 and 14). The uptake rate $k_{\text {in }}$ of $\mathrm{La}(\mathrm{OAc})_{3}$ was estimated to be $\geq 30 \mathrm{M}^{-1}$ $s^{-1}$, which was at least 100 times faster than that of $\mathrm{La}(\mathrm{OTf})_{3}$. Clearly, the counteranions played a critical role in the exceptionally slow uptake of $\mathrm{La}(\mathrm{OTf})_{3}$.

As already described, the guest uptake/release by $\mathbf{1}^{2+}$ is exceptionally slow, and this would allow us to obtain kinetically 
a
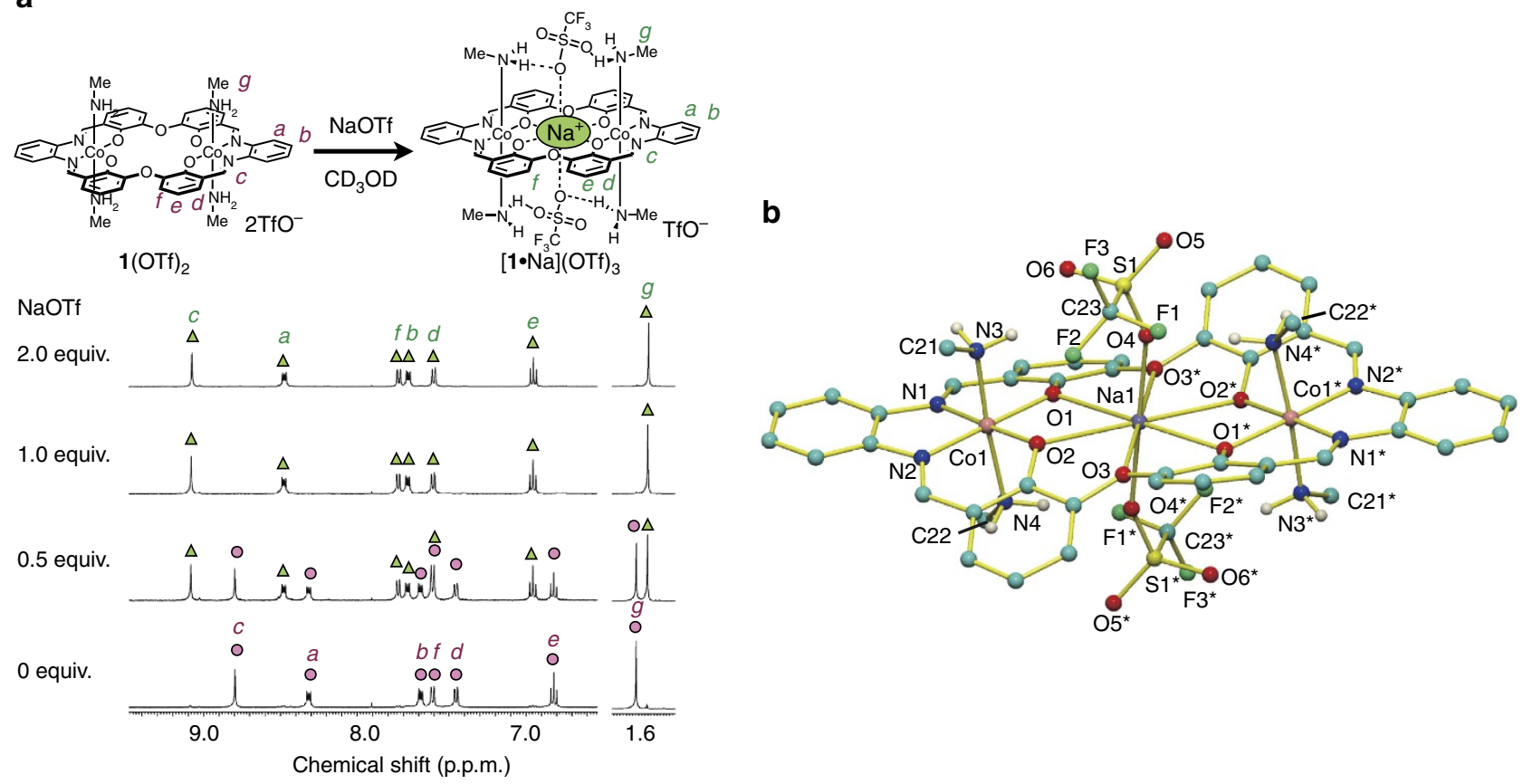

Figure 2 | $\mathbf{N a}^{+}$encapsulation by anion-capped metallohost. (a) ${ }^{1} \mathrm{H}$ NMR spectral changes of $\mathbf{1}(\mathrm{OTf})_{2}$ upon the addition of $\mathrm{NaOTf}$ in $\mathrm{CD}_{3} \mathrm{OD}(400 \mathrm{MHz}$, $\left.\left[\mathbf{1}(\mathrm{OTf})_{2}\right]=1.0 \mathrm{mM}\right)$. (b) X-ray crystal structure of $\left[\mathbf{1 \bullet N a}(\mathrm{OTf})_{2}\right](\mathrm{OTf})$. Hydrogen atoms are omitted for clarity except for those of the $\mathrm{NH}_{2}$ groups. The solvent molecules and one triflate anion are also omitted.

Table 1 | Association constants and kinetic data for the complexation between $\mathbf{1}^{2+}$ or 18-crown-6 and guest cations.

\begin{tabular}{|c|c|c|c|c|c|}
\hline Guest $^{\star}$ & Ionic radius $(\AA))^{52}$ & $\begin{array}{l}\text { Association constant } \\
\qquad K_{\mathrm{a}}\left(M^{-1}\right)\end{array}$ & \multicolumn{2}{|c|}{ Kinetic data } & $\begin{array}{l}\text { Association constant of 18-crown-6 } \\
\qquad K_{\mathrm{a}}\left(\mathrm{M}^{-1}\right)\end{array}$ \\
\hline $\mathrm{Mg}^{2+}$ & 1.03 & n.d. ${ }^{\dagger}$ & n.d. ${ }^{\dagger}$ & n.d. ${ }^{\dagger}$ & $4.1 \times 10^{3}$ (ref. 53) \\
\hline $\mathrm{Ca}^{2+}$ & 1.26 & $9.5 \times 10^{6 \ddagger}$ & $\geq 30$ & $<1^{\oplus}$ & $9.1 \times 10^{3}$ (ref. 53) \\
\hline $\mathrm{La}^{3+}$ & 1.30 & $2.4 \times 10^{6 \ddagger}$ & $\sim 10^{-2 \|}$ & $\sim 10^{-8}$ & $5.5 \times 10^{3}($ ref. 53$)$ \\
\hline $\mathrm{Na}^{+}$ & 1.32 & $8.5 \times 10^{6 \ddagger}$ & $\geq 30$ & $<1$ & $2.9 \times 10^{4}($ ref. 53$)$ \\
\hline $\mathrm{Cs}^{+}$ & 1.88 & $2.3 \times 10^{3 \S}$ & $6.9 \times 10^{6}$ & 3,000 & $3.1 \times 10^{4}$ (ref. 53) \\
\hline \multicolumn{6}{|c|}{ 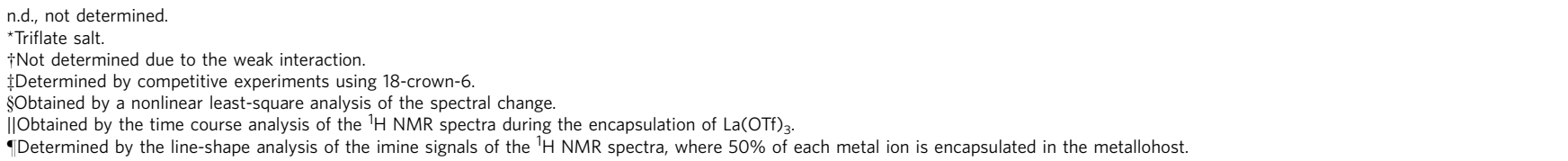 } \\
\hline
\end{tabular}

trapped states as depicted in Fig. 1b(i). In order to use this system for kinetically controlled switching, it is necessary to accelerate it by removing or lowering the kinetic barrier (Fig. $1 \mathrm{~b}(\mathrm{ii})$ ). Since the counteranions $\left(\mathrm{TfO}^{-}\right.$and $\mathrm{AcO}^{-}$) significantly affect the guest uptake/release rates of $\mathbf{1}^{2+}$, we expected that exchanges of the anion caps would lower the barrier and trigger the guest uptake/release. Thus, we made an on-demand guest exchange system driven by the anion cap replacement.

We chose $\mathrm{K}^{+}$and $\mathrm{La}^{3+}$ as the guests to obtain a kinetically trapped state because $\mathrm{La}(\mathrm{OTf})_{3}$ was more strongly bound $\left(K_{\mathrm{a}}=2.4 \times 10^{6} \mathrm{M}^{-1}\right)$ than KOTf $\left(K_{\mathrm{a}}=1.1 \times 10^{6} \mathrm{M}^{-1}\right)$, but more slowly taken up $\left(k_{\text {in }} \approx 10^{-2} \mathrm{M}^{-1} \mathrm{~s}^{-1}\right)$ than KOTf $\left(k_{\text {in }}=1.9 \times 10^{7} \mathrm{M}^{-1} \mathrm{~s}^{-1}\right)$. As expected from the thermodynamic and kinetic data, we successfully generated the kinetically trapped state $\left\{[1 \bullet \mathrm{K}]^{3+}+\mathrm{La}^{3+}\right\}$ when KOTf (1 equiv) and $\mathrm{La}(\mathrm{OTf})_{3}$
(2 equiv) were added to the metallohost $\mathbf{1}(\mathrm{OTf})_{2}$ at once (Figs $3 \mathrm{a}(\mathrm{i})$ and $4(\mathrm{i})$ ). The kinetically formed $\mathrm{K}^{+}$complex would be converted to the thermodynamically more stable $\mathrm{La}^{3+}$ complex according to the difference in the association constants. However, this guest exchange was found to be very slow; the $\mathrm{K}^{+}$complex was still dominant even after 14 days (Figs $3 a(i), b(i)$ and 4(ii) and Supplementary Fig. 20). It should be noted that the reverse reaction from $[1 \bullet \mathrm{La}]^{5+}$ to $[1 \bullet \mathrm{K}]^{3+}$ did not take place at all when KOTf was added to the $\mathrm{La}^{3+}$ complex (Fig. 4(iii) and Supplementary Fig. 23). Since both of the two states, $\left\{[1 \bullet \mathrm{K}]^{3+}+\mathrm{La}^{3+}\right\}$ and $\left\{[1 \bullet \mathrm{La}]^{5+}+\mathrm{K}^{+}\right\}$, were observable, the thermodynamically less stable state, $\left\{[1 \bullet \mathrm{K}]^{3+}+\mathrm{La}^{3+}\right\}$, is thought to be a very stable kinetically trapped state.

Interestingly, the addition of acetate ion markedly changed this situation. When 3 equiv of $\mathrm{Bu}_{4} \mathrm{NOAc}$ was present from the 
a

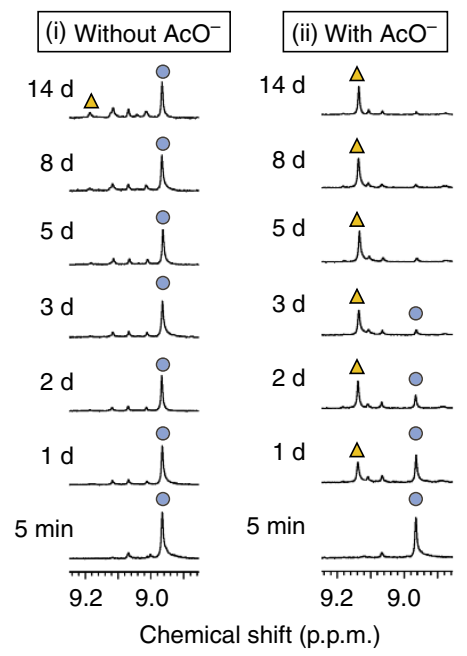

b

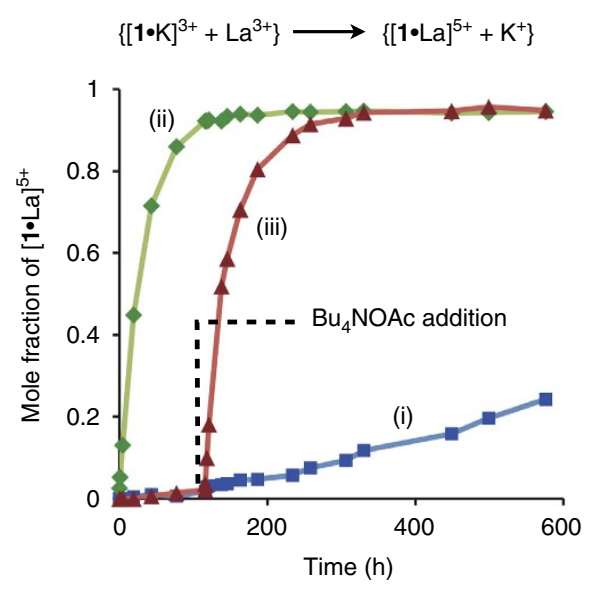

Figure 3 | Time course analysis of guest exchange from $[\mathbf{1 \bullet} \mathbf{K}]^{\mathbf{3}+}$ to $[1 \bullet \mathbf{L a}]^{\mathbf{5}+}$. (a) Changes of the imine signals in the ${ }^{1} \mathrm{H}$ NMR spectra (blue circle: $\mathrm{K}^{+}$ complex and yellow triangle: $\mathrm{La}^{3+}$ complex) in the absence/presence of tetrabutylammonium acetate $\left(1.0 \mathrm{mM}, \mathrm{CD}_{3} \mathrm{OD}, 25^{\circ} \mathrm{C}\right)$. $(\mathbf{b}) \mathrm{Plots}$ of mole fractions of $[\mathbf{1} \bullet \mathrm{La}]^{5+}$ versus time after addition of $\mathrm{K}^{+}$and $\mathrm{La}^{3+}$

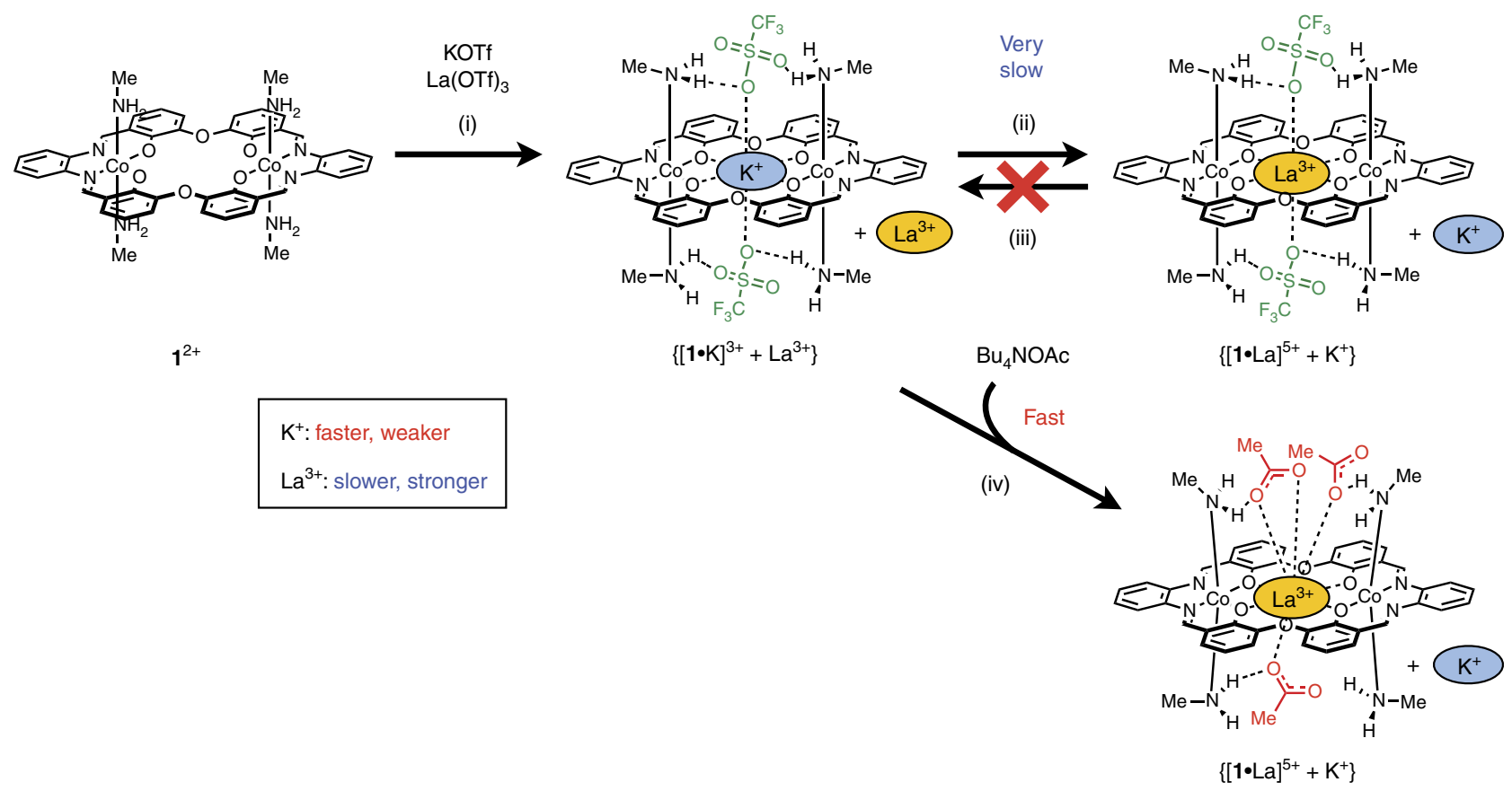

Figure 4 | Guest recognition and exchange behaviours of $\mathbf{1}(\mathbf{O T f})_{2}$. When KOTf and La(OTf) 3 were added to the metallohost $\mathbf{1}$ (OTf) ${ }_{2}$ at once, the kinetically trapped state $\left\{[\mathbf{1 0 K}]^{3+}+\mathrm{La}^{3+}\right\}$ was generated (i). While the conversion from the kinetically formed $\mathrm{K}^{+}$complex to the thermodynamically more stable $\mathrm{La}^{3+}$ complex was exceptionally slow (ii, iii), the guest exchange was significantly accelerated by the addition of tetrabutylammonium acetate (iv).

beginning, the exchange of $\mathrm{K}^{+}$with $\mathrm{La}^{3+}$ took place much faster (Figs 3a(ii),b(ii) and 4(iv) and Supplementary Fig. 21). The reaction was accelerated by $\sim 75$ times, which was estimated from the initial rates. Obviously, the addition of $\mathrm{Bu}_{4} \mathrm{NOAc}$ drastically accelerated the guest exchange. It is noteworthy that we can accelerate this metal exchange at any stage of the reaction. For example, when 3 equiv of $\mathrm{Bu}_{4} \mathrm{NOAc}$ was added after $120 \mathrm{~h}$, $[1 \bullet \mathrm{La}]^{5+}$ started to immediately increase after the addition (Fig. 3b(iii) and Supplementary Fig. 22). Since almost no metal exchange had occurred before the addition, the acetate ion acted as a trigger to initiate the guest exchange reaction from the kinetically trapped state.
In the X-ray crystal structure (Fig. 5), the complex cation $[1 \bullet \mathrm{La}]^{5+}$ has three acetate and two triflate counteranions, among which only the three acetate ions coordinated to the $\mathrm{La}^{3+}$. This clearly demonstrates the complete binding selectivity of $[1 \bullet \mathrm{La}]^{5+}$ for acetate ion over triflate ion. The higher coordination ability of the acetate ions to $\mathrm{La}^{3+}$ probably contributes to the acceleration of the exchange of $\mathrm{K}^{+}$with $\mathrm{La}^{3+}$ in the metallohost $\mathbf{1}(\mathrm{OTf})_{2}$ (Fig. 4).

\section{Discussion}

We synthesized a dicationic cobalt(III) metallohost $\mathbf{1}(\mathrm{OTf})_{2}$ that has capping sites to hold the anion caps. The guest ion 


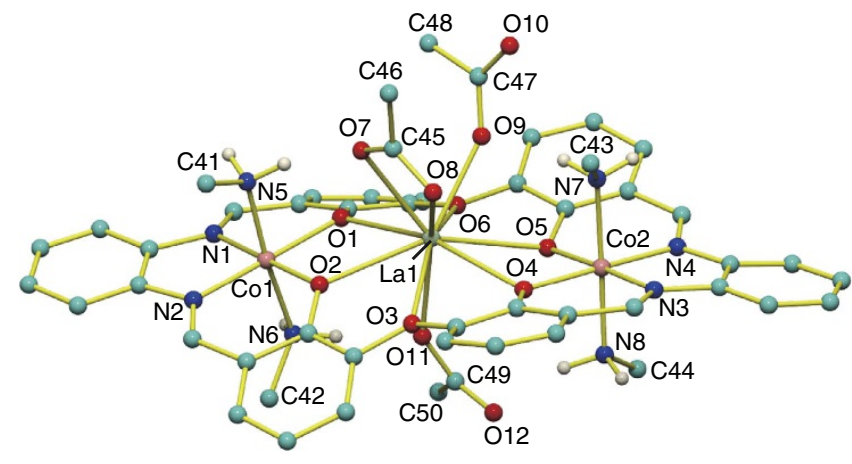

Figure 5 | X-ray crystal structure of [1॰La(OAC) 3 (OTf) 2 . Hydrogen atoms are omitted for clarity except for those of the $\mathrm{NH}_{2}$ groups. The solvent molecules and two triflate anions are also omitted.

$\left(\mathrm{Na}^{+}, \mathrm{K}^{+}, \mathrm{Rb}^{+}, \mathrm{Cs}^{+}, \mathrm{Ca}^{2+}\right.$ or $\left.\mathrm{La}^{3+}\right)$ was encapsulated in the $\mathrm{O}_{6}$ cavity of $\mathbf{1}(\mathrm{OTf})_{2}$ in such a way that the two counteranions capped the guest cation. Uptake of $\mathrm{La}(\mathrm{OTf})_{3}$ by $\mathbf{1}(\mathrm{OTf})_{2}$ was exceptionally slow (half-life $\sim 10 \mathrm{~h}$ ) probably due to the capping effect of the triflate ion. This anion-capped structure enabled us to construct a host-guest system in which the guest exchange is accelerated in a time-programmable and on-demand manner. We believe that these results will open the way for the development of new functional materials in which the desired function is triggered by guest recognition not only by chemical stimuli but also by physical stimuli such as light or heat.

\section{Methods}

Materials and methods. Reagents and solvents were purchased from commercial sources and used without further purification. ${ }^{1} \mathrm{H}$ NMR spectra were recorded on a JEOL JNM-ECS $400(400 \mathrm{MHz})$. Chemical shifts in $\mathrm{CD}_{3} \mathrm{OD}$ were referenced with respect to the solvent residual peak (3.31 p.p.m.). Electrospray ionization time of flight (ESI-TOF) mass spectra were recorded on a Bruker Daltonics micrOTOF II spectrometer.

Synthesis of $\left[\mathrm{LCO}_{2}\left(\mathrm{CH}_{3} \mathrm{NH}_{2}\right)_{4}\right](\mathrm{OTf})_{2}\left(\mathbf{1}(\mathrm{OTf})_{2}\right)$. A solution of macrocyclic ligand $\mathrm{H}_{4} \mathrm{~L}(149 \mathrm{mg}, 0.201 \mathrm{mmol})^{44,45}$ in chloroform $(40 \mathrm{ml})$ was mixed with a solution of cobalt(II) acetate tetrahydrate $(108 \mathrm{mg}, 0.434 \mathrm{mmol})$ in methanol $(12 \mathrm{ml})$, a solution of tetrabutylammonium trifluoromethanesulfonate $(783 \mathrm{mg}$, $2.00 \mathrm{mmol}$ ) in methanol $(12 \mathrm{ml})$ and then methylamine (40\% in methanol, $2.0 \mathrm{ml})$. The resulting solution was stirred under air for $12 \mathrm{~h}$. After the solution was concentrated to dryness, the residue was dissolved in acetonitrile and diethyl ether was added. The precipitated crude product was collected and dissolved in a small amount of methanol containing methylamine ( $40 \%$ in methanol, $1.0 \mathrm{ml})$. The solution was left for $3 \mathrm{~h}$ and then diethyl ether was added to give precipitates, which were collected by filtration. After repeating the purification by reprecipitation, the product was collected by filtration to give $\mathbf{1}(\mathrm{OTf})_{2}(150 \mathrm{mg}, 0.125 \mathrm{mmol}, 62 \%)$ as a reddish brown powder. ${ }^{1} \mathrm{H}$ NMR $\left(400 \mathrm{MHz}, \mathrm{CD}_{3} \mathrm{OD}\right) \delta 8.80(\mathrm{~s}, 4 \mathrm{H}), 8.34-8.29$ (m, $4 \mathrm{H}), 7.61-7.56(\mathrm{~m}, 4 \mathrm{H}), 7.51(\mathrm{dd}, J=7.8,1.4 \mathrm{~Hz}, 4 \mathrm{H}), 7.35(\mathrm{dd}, J=7.8,1.4 \mathrm{~Hz}$, $4 \mathrm{H}), 6.72(\mathrm{t}, J=7.8 \mathrm{~Hz}, 4 \mathrm{H}), 1.64(\mathrm{~s}, 12 \mathrm{H})$. ESI-MS $\mathrm{m} / z 1047.1[\mathbf{1}+\mathrm{OTf}]^{+}$. Anal. Calcd for $\mathrm{C}_{46} \mathrm{H}_{44} \mathrm{Co}_{2} \mathrm{~F}_{6} \mathrm{~N}_{8} \mathrm{O}_{12} \mathrm{~S}_{2} \bullet 3 \mathrm{MeOH} \bullet 2 \mathrm{H}_{2} \mathrm{O}: \mathrm{C}, 44.28 ; \mathrm{H}, 4.55 ; \mathrm{N}, 8.43$. Found: C, $44.42 ; \mathrm{H}, 4.81 ; \mathrm{N}, 8.76$.

X-ray crystallography. Intensity data were collected on a Rigaku Mercury diffractometer (with Mo K $\alpha$ radiation, $\lambda=0.71073 \AA$ ) or a Bruker SMART APEX II diffractometer (with $\mathrm{Cu} \mathrm{K} \alpha$ radiation, $\lambda=1.54178 \AA$ ). The data were corrected for Lorentz and polarization factors and for absorption by semi-empirical methods based on symmetry-equivalent and repeated reflections. The structures were solved by direct methods (SHELXS 97 (ref. 49) or SHELXT ${ }^{50}$ ) and refined by full-matrix least squares on $F^{2}$ using SHELXL 2014 (ref. 51) (Supplementary Tables 1-3 and Supplementary Figs 15-19).

Data availability. Crystallographic data in this paper can be obtained free of charge via www.ccdc.cam.ac.uk/data_request/cif (or from the Cambridge Crystallographic Data Centre, 12 Union Road, Cambridge CB2 1EZ, UK). The deposit numbers are $1525963\left(\left[1 \bullet \mathrm{K}(\mathrm{OTf})_{2}\right](\mathrm{OTf})\right), 1525964\left(\left[1 \bullet \mathrm{La}(\mathrm{OAc})_{3}\right](\mathrm{OTf})_{2}\right)$, $1525965\left(\left[1 \bullet \mathrm{Na}\left(\mathrm{OTf}_{2}\right](\mathrm{OTf})\right), 1525966\left(\left[1 \bullet \mathrm{Ca}\left(\mathrm{OTf}_{2}\right](\mathrm{OTf})_{2}\right)\right.\right.$ and 1525967
$\left(\mathbf{1}(\mathrm{OTf})_{2}\right)$. All other data are available in this article and in the Supplementary Information file.

\section{References}

1. Boulas, P. L., Gómez-Kaifer, M. \& Echegoyen, L. Electrochemistry of supramolecular systems. Angew. Chem. Int. Ed. 37, 216-247 (1998).

2. Takeuchi, M., Ikeda, M., Sugasaki, A. \& Shinkai, S. Molecular design of artificial molecular and ion recognition systems with allosteric guest responses. Acc. Chem. Res. 34, 865-873 (2001).

3. Nabeshima, T. \& Akine, S. Functional supramolecular systems with highly cooperative and responding properties. Chem. Rec. 8, 240-251 (2008).

4. Qu, D.-H., Wang, Q.-C., Zhang, Q.-W., Ma, X. \& Tian, H. Photoresponsive host-guest functional systems. Chem. Rev. 115, 7543-7588 (2015).

5. McConnell, A. J., Wood, C. S., Neelakandan, P. P. \& Nitschke, J. R. Stimuli-responsive metal-ligand assemblies. Chem. Rev. 115, 7729-7793 (2015).

6. Seward, E. M., Hopkins, R. B., Sauerer, W., Tam, S.-W. \& Diederich, F. Redox-dependent binding ability of a flavin cyclophane in aqueous solution: hydrophobic stacking versus cavity-inclusion complexation. J. Am. Chem. Soc. 112, 1783-1790 (1990).

7. Jeon, W. S. et al. Molecular loop lock: a redox-driven molecular machine based on a host-stabilized charge-transfer complex. Angew. Chem. Int. Ed. 44, 87-91 (2005).

8. Croué, V., Goeb, S., Szalóki, G., Allain, M. \& Sallé, M. Reversible guest uptake/ release by redox-controlled assembly/disassembly of a coordination cage. Angew. Chem. Int. Ed. 55, 1746-1750 (2016).

9. Jeon, Y.-M., Kim, J., Whang, D. \& Kim, K. Molecular container assembly capable of controlling binding and release of its guest molecules: reversible encapsulation of organic molecules in sodium ion complexed cucurbituril. J. Am. Chem. Soc. 118, 9790-9791 (1996).

10. Whang, D., Heo, J., Park, J. H. \& Kim, K. A molecular bowl with metal ion as bottom: reversible inclusion of organic molecules in cesium ion complexed cucurbituril. Angew. Chem. Int. Ed. 37, 78-80 (1998).

11. Chan, A. K.-W., Lam, W. H., Tanaka, Y., Wong, K. M.-C. \& Yam, V. W.-W. Multiaddressable molecular rectangles with reversible host-guest interactions: modulation of $\mathrm{pH}$-controlled guest release and capture. Proc. Natl Acad. Sci. USA 112, 690-695 (2015).

12. Shinkai, S., Nakaji, T., Ogawa, T., Shigematsu, K. \& Manabe, O. Photoresponsive crown ethers. 2. Photocontrol of ion extraction and ion transport by a bis(crown ether) with a butterfly-like motion. J. Am. Chem. Soc. 103, 111-115 (1981).

13. Irie, M. \& Kato, M. Photoresponsive molecular tweezers. Photoregulated ion capture and release using thioindigo derivatives having ethylenedioxy side groups. J. Am. Chem. Soc. 107, 1024-1028 (1985).

14. Blank, M., Soo, L. M., Wassermann, N. H. \& Erlanger, B. F. Photoregulated ion binding. Science 214, 70-72 (1981).

15. Han, M. et al. Light-triggered guest uptake and release by a photochromic coordination cage. Angew. Chem. Int. Ed. 52, 1319-1323 (2013).

16. Nabeshima, T., Yoshihira, Y., Saiki, T., Akine, S. \& Horn, E. Remarkably large positive and negative allosteric effects on ion recognition by the formation of a novel helical pseudocryptand. J. Am. Chem. Soc. 125, 28-29 (2003).

17. Hiraoka, S., Harano, K., Shiro, M. \& Shionoya, M. Quantitative dynamic interconversion between $\mathrm{Ag}^{\mathrm{I}}$-mediated capsule and cage complexes accompanying guest encapsulation/release. Angew. Chem. Int. Ed. 44, 2727-2731 (2005).

18. Lingrel, J. B. \& Kuntzweiler, T. $\mathrm{Na}^{+}, \mathrm{K}^{+}$-ATPase. J. Biol. Chem. 269, 19659-19662 (1994).

19. Kaplan, J. H. Biochemistry of Na,K-ATPase. Annu. Rev. Biochem. 71, 511-535 (2002).

20. Ludlow, R. F. \& Otto, S. Systems chemistry. Chem. Soc. Rev. 37, 101-108 (2008).

21. Mattia, E. \& Otto, S. Supramolecular systems chemistry. Nat. Nanotechnol. 10, 111-119 (2015).

22. Yang, L., Tan, X., Wang, Z. \& Zhang, X. Supramolecular polymers: historical development, preparation, characterization, and functions. Chem. Rev. 115, 7196-7239 (2015).

23. Yan, Y., Huang, J. \& Tang, B. Z. Kinetic trapping-a strategy for directing the self-assembly of unique functional nanostructures. Chem. Commun. 52, 11870-11884 (2016).

24. Shigeno, M., Kushida, Y. \& Yamaguchi, M. Molecular switching involving metastable states: molecular thermal hysteresis and sensing of environmental changes by chiral helicene oligomeric foldamers. Chem. Commun. 52, 4955-4970 (2016).

25. Korevaar, P. A. et al. Pathway complexity in supramolecular polymerization. Nature 481, 492-497 (2012).

26. Ogi, S., Sugiyasu, K., Manna, S., Samitsu, S. \& Takeuchi, M. Living supramolecular polymerization realized through a biomimetic approach. Nat. Chem. 6, 188-195 (2014). 
27. Ogi, S., Fukui, T., Jue, M. L., Takeuchi, M. \& Sugiyasu, K. Kinetic control over pathway complexity in supramolecular polymerization through modulating the energy landscape by rational molecular design. Angew. Chem. Int. Ed. 53, 14363-14367 (2014).

28. Kang, J. et al. A rational strategy for the realization of chain-growth supramolecular polymerization. Science 347, 646-651 (2015).

29. Görl, D., Zhang, X., Stepanenko, V. \& Würthner, F. Supramolecular block copolymers by kinetically controlled co-self-assembly of planar and coretwisted perylene bisimides. Nat. Commun. 6, 7009 (2015).

30. Ogi, S., Stepanenko, V., Thein, J. \& Würthner, F. Impact of alkyl spacer length on aggregation pathways in kinetically controlled supramolecular polymerization. J. Am. Chem. Soc. 138, 670-678 (2016).

31. Palmer, L. C. \& Rebek, Jr J. The ins and outs of molecular encapsulation. Org. Biomol. Chem. 2, 3051-3059 (2004).

32. Pluth, M. D. \& Raymond, K. N. Reversible guest exchange mechanisms in supramolecular host-guest assemblies. Chem. Soc. Rev. 36, 161-171 (2007)

33. Rieth, S., Hermann, K., Wang, B.-Y. \& Badjić, J. D. Controlling the dynamics of molecular encapsulation and gating. Chem. Soc. Rev. 40, 1609-1622 (2011).

34. Zarra, S., Wood, D. M., Roberts, D. A. \& Nitschke, J. R. Molecular containers in complex chemical systems. Chem. Soc. Rev. 44, 419-432 (2015).

35. Mukhopadhyay, P., Zavalij, P. Y. \& Isaacs, L. High fidelity kinetic self-sorting in multi-component systems based on guests with multiple binding epitopes. J. Am. Chem. Soc. 128, 14093-14102 (2006).

36. de Greef, T. F. A. et al. The mechanism of ureido-pyrimidinone: 2,7-diamidonaphthyridine complexation and the presence of kinetically controlled pathways in multicomponent hydrogen-bonded systems. J. Am. Chem. Soc. 130, 5479-5486 (2008).

37. Masson, E., Lu, X., Ling, X. \& Patchell, D. L. Kinetic vs thermodynamic self-sorting of cucurbit[6]uril, cucurbit[7]uril, and a spermine derivative. Org. Lett. 11, 3798-3801 (2009).

38. Tang, H. et al. Guest binding dynamics with cucurbit[7]uril in the presence of cations. J. Am. Chem. Soc. 133, 20623-20633 (2011).

39. Jiang, W., Ajami, D. \& Rebek, Jr J. Alkane lengths determine encapsulation rates and equilibria. J. Am. Chem. Soc. 134, 8070-8073 (2012).

40. Chapin, J. C., Kvasnica, M. \& Purse, B. W. Molecular encapsulation in pyrogallolarene hexamers under nonequilibrium conditions. J. Am. Chem. Soc. 134, 15000-15009 (2012).

41. Gan, Q. et al. Identification of a foldaxane kinetic byproduct during guestinduced single to double helix conversion. J. Am. Chem. Soc. 134, 15656-15659 (2012).

42. Smulders, M. M. J., Zarra, S. \& Nitschke, J. R. Quantitative understanding of guest binding enables the design of complex host-guest behavior. J. Am. Chem. Soc. 135, 7039-7046 (2013).

43. Tootoonchi, M. H., Yi, S. \& Kaifer, A. E. Detection of isomeric microscopic host-guest complexes. A time-evolving cucurbit[7] uril complex. J. Am. Chem. Soc. 135, 10804-10809 (2013).

44. Akine, S., Utsuno, F. \& Nabeshima, T. Highly efficient regulation of cation recognition and promotion of self-assembly by metalation of a macrocyclic bis $\left(\mathrm{N}_{2} \mathrm{O}_{2}\right)$ ligand with nickel(II). Chem. Commun. 46, 1029-1031 (2010).

45. Akine, S. et al. Synthesis, ion recognition ability, and metal-assisted aggregation behavior of dinuclear metallohosts having a bis(saloph) macrocyclic ligand. Inorg. Chem. 55, 810-821 (2016).

46. Shchori, E., Jagur-Grodzinski, J. \& Shporer, M. Kinetics of complexation of macrocyclic polyethers with sodium ions by nuclear magnetic resonance spectroscopy. II. Solvent effects. J. Am. Chem. Soc. 95, 3842-3846 (1973).

47. Strasser, B. O. \& Popov, A. I. Influence of solvent properties on the kinetics of complexation of the sodium ion with 18-crown-6. J. Am. Chem. Soc. 107, 7921-7924 (1985).

48. Liesegang, G. W., Farrow, M. M., Vazquez, F. A., Purdie, N. \& Eyring, E. M. Ultrasonic absorption kinetic studies of the complexation of aqueous $\mathrm{Li}^{+}$,
$\mathrm{Na}^{+}, \mathrm{Rb}^{+}, \mathrm{Tl}^{+}, \mathrm{Ag}^{+}, \mathrm{NH}_{4}^{+}$, and $\mathrm{Ca}^{2+}$ by 18-crown-6. J. Am. Chem. Soc. 99, 3240-3243 (1977).

49. Sheldrick, G. M. A short history of SHELX. Acta Crystallogr. A64, 112-122 (2008).

50. Sheldrick, G. M. SHELXT-Integrated space-group and crystal-structure determination. Acta Crystallogr. A71, 3-8 (2015).

51. Sheldrick, G. M. Crystal structure refinement with SHELXL. Acta Crystallogr. C71, 3-8 (2015).

52. Shannon, R. D. Revised effective ionic radii and systematic studies of interatomic distances in halides and chalcogenides. Acta Crystallogr. A32, 751-767 (1976).

53. Izatt, R. M., Pawlak, K. \& Bradshaw, J. S. Thermodynamic and kinetic data for macrocycle interaction with cations and anions. Chem. Rev. 91, 1721-2085 (1991).

54. Smetana, A. J. \& Popov, A. I. Lithium-7 nuclear magnetic resonance and calorimetric study of lithium crown complexes in various solvents. J. Sol. Chem. 9, 183-196 (1980).

\section{Acknowledgements}

This work was supported in part by JSPS KAKENHI (Grant Number JP16H06510 (Coordination Asymmetry) and JP26288022), the Noguchi Institute and Kanazawa University CHOZEN Project. We thank Dr Kenji Yoza (Bruker AXS KK) for the X-ray data collection for $\left[\mathbf{1} \bullet \mathrm{K}(\mathrm{OTf})_{2}\right](\mathrm{OTf}),\left[\mathbf{1} \bullet \mathrm{Ca}(\mathrm{OTf})_{2}\right](\mathrm{OTf})_{2}$ and $\left[\mathbf{1} \bullet \mathrm{La}(\mathrm{OAc})_{3}\right](\mathrm{OTf})_{2}$

\section{Author contributions}

S.A. initiated the project and Y.S. designed the research; C.M. carried out all the experiments under the guidance of Y.S. and S.A. All authors contributed to analysing and interpreting the data, and Y.S. and S.A. co-wrote the manuscript.

\section{Additional information}

Supplementary Information accompanies this paper at http://www.nature.com/ naturecommunications

Competing interests: The authors declare no competing financial interests.

Reprints and permission information is available online at http://npg.nature.com/ reprintsandpermissions/

How to cite this article: Sakata, Y. et al. Anion-capped metallohost allows extremely slow guest uptake and on-demand acceleration of guest exchange. Nat. Commun. 8, 16005 doi: 10.1038/ncomms16005 (2017).

Publisher's note: Springer Nature remains neutral with regard to jurisdictional claims in published maps and institutional affiliations.

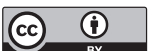

Open Access This article is licensed under a Creative Commons Attribution 4.0 International License, which permits use, sharing, adaptation, distribution and reproduction in any medium or format, as long as you give appropriate credit to the original author(s) and the source, provide a link to the Creative Commons license, and indicate if changes were made. The images or other third party material in this article are included in the article's Creative Commons license, unless indicated otherwise in a credit line to the material. If material is not included in the article's Creative Commons license and your intended use is not permitted by statutory regulation or exceeds the permitted use, you will need to obtain permission directly from the copyright holder. To view a copy of this license, visit http://creativecommons.org/ licenses/by/4.0/

(C) The Author(s) 2017 